\title{
AGEISM - ANALYSIS OF THE PROBLEM IN THE CONTEXT OF THE HEALTHCARE
}

\author{
T. Paskaleva*, Zh. Tencheva, K. Kostov \\ Department "Healthcare", Branch Haskovo of the Trakia University, Stara Zagora, Bulgaria
}

\begin{abstract}
Ageing as a phase of human life is connected with a number of specific problems, originating from the natural alternations in the physical, psychical, social and economic status. During the past years the issue of the age discrimination is getting more and more actual and pressing, significant and also a barrier against the shaping of a tolerant social atmosphere.

The phenomenon ,ageism“ places its challenges before the contemporary education, and it requires a profound research and application of possibilities for its overcoming via adequate educational programs and models.

The aim of the current research is to be studied the arrangements and the stereotypes in the students' attitude towards the elderly people. In the research, which was conducted, participated 70 students from the specialty "Nurse" in Branch Haskovo of the Trakia University.

The results of this research give us a good reason in the training and education of the students to be applied different interactive techniques and approaches, which present positive role models of ageing and form new types of attitude towards the elderly generation.
\end{abstract}

Key words: ageism, age discrimination, elderly people, students, healthcare

\section{INTRODUCTION}

In the last decades the world's demographic panorama connected with ageing of the population has an alarming character, including the long-term prospective. According to the WHO two billion people will be over 60 years old in 2050, which is three times more than their number in the 2000. Bulgaria also suffers the strikes of the demographic crisis. In 2025 every 1 out of 5 Bulgarians will be aged over 65. In 1990 only 1 out of 13 was over 65. [1].

Ageing, as a phase of the human life is connected with a number of specific problems, coming from the natural changes in the physical, psychical, social and economic status. During the past years the issue of the age discrimination is getting more and more actual, significant and also a barrier in the formation of a tolerant society.

\footnotetext{
* Correspondence to: Tanya Paskaleva, Department "Healthcare" Branch Haskovo of the Trakia University, Bulgaria, paskaleva666@abv.bg
}

Over 40 years ago Robert Butler for the first time defines the notion 'ageism', as a "process of systematic stereotyping and discrimination against a certain group of people, just because they are old". Later on other authors discuss and research this morbid issue, and they present it and interpret it really on a large scale. This gives the possibility to be featured some characteristic of the ageism elements prejudiced viewpoints to the elderly people and the ageing process; discriminating practices against the elderly people and institutional practices and policies that support stereotypes towards the elderly people $[2,3]$.

In this connection the analysis of the 'ageism' assumes understanding of the essence and the links between the stereotypes, prejudices and discrimination. The stereotypes belong to the sphere of the mind and are not necessarily negative.

They are a result from inscribing identical characteristics of a person from a definite group, irrespective of the existing differences between the members of this 
group. Prejudices belong to the sphere of the emotions, and they are an expression of negative or hostile attitude towards a given person and are characterized with a three-componential structural model: cognitive component (conviction), affective component (feelings) and behavioral component. Discrimination is a negative attitude towards people, motivated by their appurtenance and it hinders tolerance.

Despite the fact that the concept of the age discrimination has American origin, some research show that it also appears in the Western societies. Our country is not an exception. The examples that we can point out have a different form and appear in different spheres of the social life healthcare, social activities, employment and others.

Some research from 2009 state that in Bulgaria mostly widespread is the age discrimination (58\%), followed by the indication 'harmed' (47\%) and ethnical origin $(40 \%)$ [4].

The factors that affect and influence these processes in our country are mostly connected to the economic crisis, but we also needn't underestimate the negative changes in the relations between the generations and the value position about the ageing.

In his works Erdman Palmer analyses the most widespread stereotypic beliefs about the elderly people: increased depression; lack of flexibility; less workable and productive, which in fact are owing to different diseases. Other common wrong beliefs are that the elderly are miserable and suppressed, dependent and irritable. The image of the elder person in the imagination of the contemporary human being has more negative than positive features. These stereotypes are often supported by the cultural tradition, strengthened by the media and the social surrounding.

The above specified negative attitudes place the elderly people in the position of a rejected generation, deprived of understanding, compassion, and support. In this way is generated a prerequisite for the decline in the opportunities for adaptation of the elderly and it is also a risky factor for social insecurity. The age discrimination has underlying negative resonance on the aims and tasks of the coming decade, and namely providing adequate conditions and satisfactory care level in order to be achieved a better quality of life of the elder population.

Working with elder people is one of the most difficult from psychological point of view activity, it creates serious challenges for those who work and are in direct and non-stop interaction with this age group.

When carrying out geriatric care the nurse is required to:

- Carrying out general and specific nursing care for the sick people in advanced years and old-aged people.

- Building an individual and optimal behavioral model of communication with the elderly people.

- Effective, competent and team solving of the medico-social and psychological problems of the elderly people.

In professional and ethical plan in the work of the nurse are intolerable to be seen discrimination practices based on age, but research show that in the sphere of the healthcare for the elderly population such deeds can be detected and they are determined in several main directions:

- Tendency to neglecting the health needs of the elderly people;

- Lack of empathy while caring for the people;

- Lack or insufficient desire to increase the professional qualification of the medical specialists in the sphere of the geriatric practices;

- Refusing or delaying medical help for many elderly patients and others [5]

The aim of the following research is to be studied the frames and stereotypes in the attitude of the students to the elderly people.

\section{MATERIALS AND METHODS}

There has been conducted an anonymous questionnaire among 70 students from the specialty "Nurse" from Branch Haskovo of the Trakia University in April and May 2015. For this reason there has been developed an anonymous questionnaire form, containing open and close questions. The results of the conducted research were statistically processed, and the graphs were made with Microsoft Excel.

\section{RESULTS AND DISCUSSION}

The frames and the stereotypes, connected to age and ageing, have a significant influence at two levels: interpersonal - on the relationships, desires and acceptable 
social roles, inscribed on every definite age group and on the other hand, intrapersonal - influence the self-assessment and the perception of the self of every individual in the process of age changes [6].

Table 1. Division of the questioned according to gender and age

\begin{tabular}{|l|l|l|l|l|l|l|l|}
\hline \multirow{2}{*}{ year } & \multicolumn{2}{|c|}{ gender } & \multicolumn{5}{c|}{ age } \\
\cline { 2 - 9 } & men & women & $18-20$ & $21-25$ & $26-35$ & $36-40$ & over 45 \\
\hline $1^{\text {st }}$ year & 1 & 19 & 16 & 1 & 2 & 1 & - \\
\hline $2^{\text {nd }}$ year & - & 25 & 9 & 12 & 2 & 1 & 1 \\
\hline $3^{\text {rd }}$ year & 2 & 23 & 9 & 12 & 2 & 2 & - \\
\hline
\end{tabular}

The young generation has no definite concept about the life of the elderly people; their only example can be the communication and their observations on their grandparents, as a model that gives them information about the psychological peculiarities, activities and behavior of the elderly person.

Most of the students associate old age with illness, that's why most of the questioned
$87 \%$ describe and characterize the elderly person with negative features - sick, helpless, passive, irritable, lonely, indecisive, tired, capricious, cross, impatient, unmotivated. Only $13 \%$ of the respondents think that elderly people are: wise, experienced, trustful, kind, inquiring, humble, communicative, sensible and cheerful.

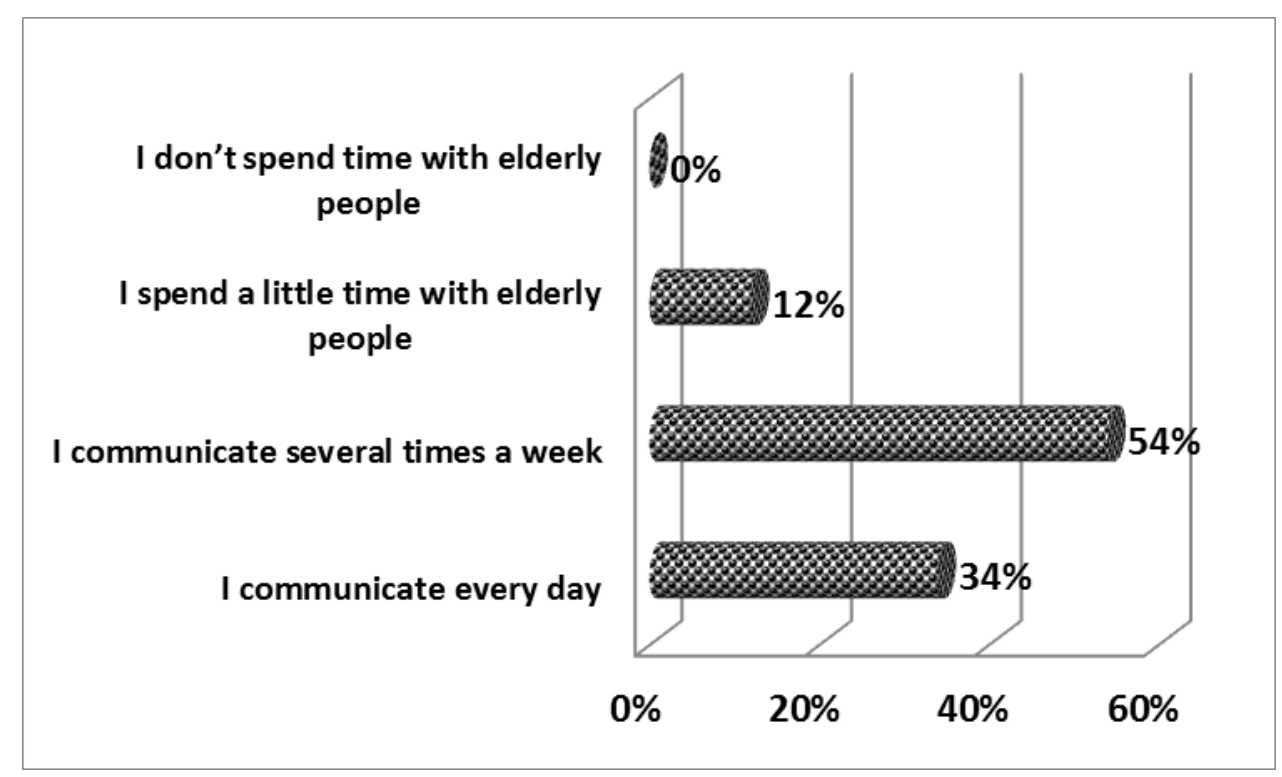

Figure 1. How do you usually spend your time with elderly people?

To the question: „How do you usually spend your time with elderly people? " the biggest part of the questioned $54 \%$ have stated that they communicate with them several times a week, $34 \%$ do it every day and $12 \%$ spend almost no time with old people.

The results from the answers of the question „Are there usually conflict situations between you and the elderly people? " (Figure 2) point out that 36\% of the respondents rarely (less than once in a month) fall into such situations, and $31 \%$ have the opinion that they have never had such conflicts. It is unfortunate to note that $12 \%$ confess that there are such situations quite often, and $4 \%$ almost every day, which once again underlines that conflicts between generations are no exception.

Shaping of the negative frames and stereotypes towards ageing are modeled in the childhood under the influence of the surrounding and the value traditions. The economic conditions of life in our country often require the elderly generation in the family (grandparents) to be dedicated mostly to the care and bringing up of their 
grandchildren. This is a valuable close communication which makes it possible to be conveyed precious experience and cultural traditions. The personal contact wit $\mathrm{h}$ the elderly person is often a more effective way to prevent or decrease the age discrimination.

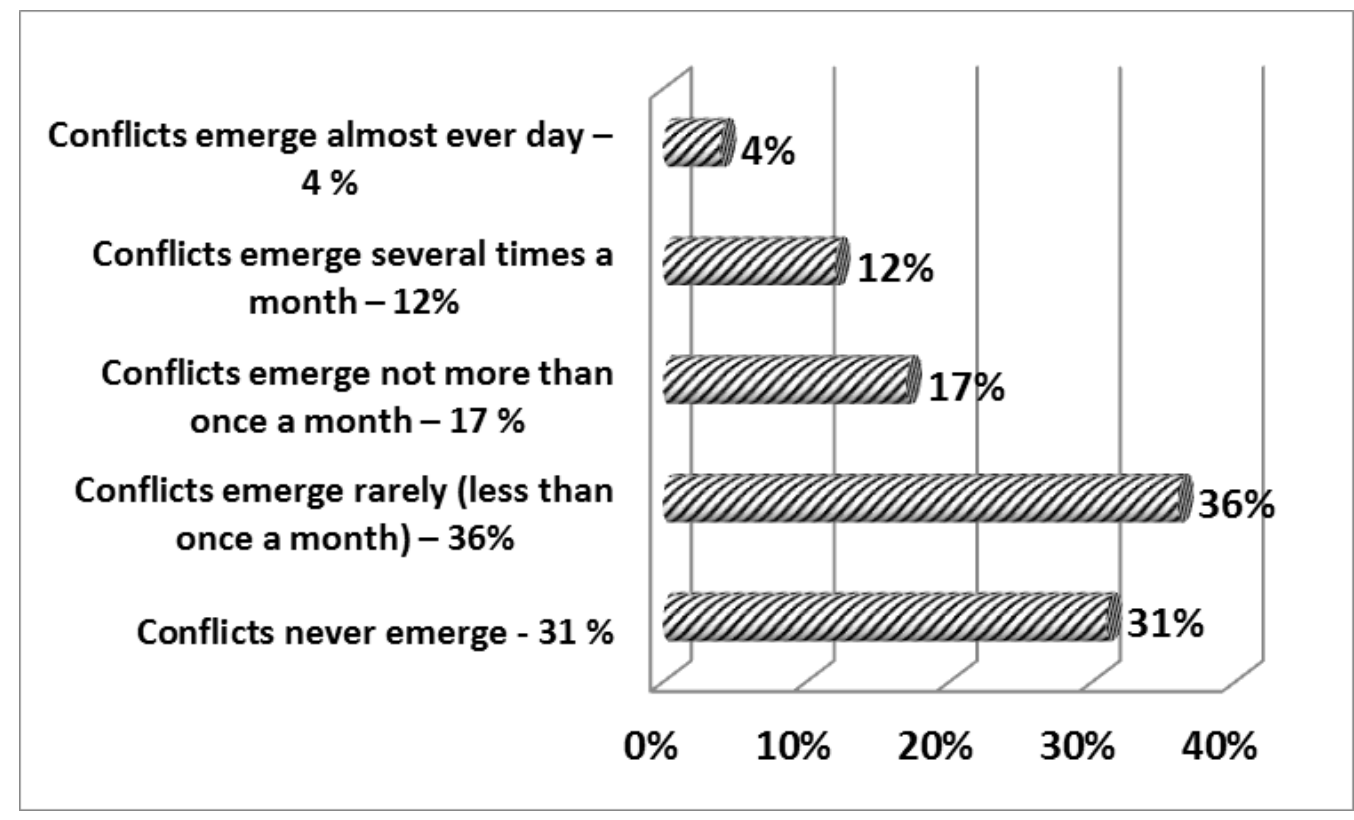

Figure 2. Are there usually conflict situations between you and the old people?

To the question: „How many grandparents do you have?" (Figure 3) 14\% (n=10) from the inquired students have pointed out that they have no grandparents, but all of the others have had the possibility to take advantage from their close communication with the elderly generation, which makes it possible to be conveyed precious experience and cultural traditions.

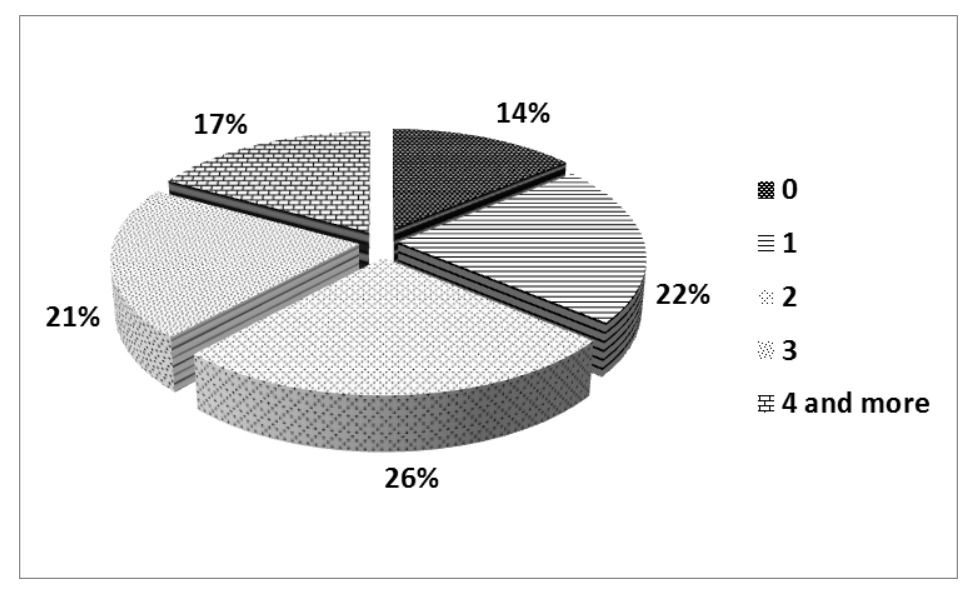

Figure 3. How many grandparents do you have?

$34 \%$ of the questioned students when in a problematic situation often seek advice from the elderly; $43 \%$ sometimes trust the experience and wisdom and $22 \%$ rarely ask for advice.

The research of the most widespread stereotypic beliefs about ageing and elderly people among the students mainly directs us to the cognitive dimensions of ageism, but the accent over the emotional reactions to the elderly is insufficient, as well as on their behavioral and communicative models, characterizing the interactions between younger and elderly people. 


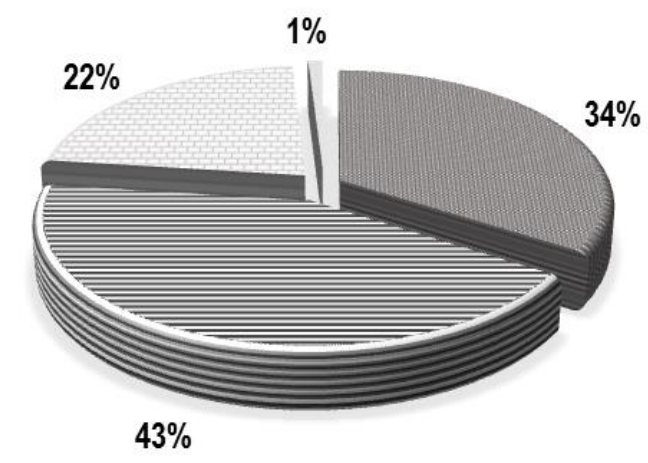

m Often

目Sometimes

ARarely

Never

Figure 4. How often do you ask for advice the elderly people?

Table 2. Stereotypic beliefs about the elderly people

\begin{tabular}{|l|l|l|l|l|l|}
\hline & $\begin{array}{c}\text { definitely } \\
\text { yes }\end{array}$ & $\begin{array}{c}\text { mostly } \\
\text { yes }\end{array}$ & $\begin{array}{c}\text { can’t } \\
\text { say }\end{array}$ & $\begin{array}{l}\text { definitely } \\
\text { no }\end{array}$ & $\begin{array}{l}\text { mostly } \\
\text { no }\end{array}$ \\
\hline $\begin{array}{l}\text { Elderly people talk only about themselves } \\
\text { and their illness }\end{array}$ & $\begin{array}{l}13 \% \\
(9)\end{array}$ & $\begin{array}{l}46 \% \\
(32)\end{array}$ & $\begin{array}{l}11 \% \\
(8)\end{array}$ & $\begin{array}{l}23 \% \\
(16)\end{array}$ & $\begin{array}{l}7 \% \\
(5)\end{array}$ \\
\hline Elderly people lead a passive way of life & $\begin{array}{l}11 \% \\
(8)\end{array}$ & $\begin{array}{l}26 \% \\
(18)\end{array}$ & $\begin{array}{l}29 \% \\
(20)\end{array}$ & $\begin{array}{l}23 \% \\
(16)\end{array}$ & $\begin{array}{l}11 \% \\
(8)\end{array}$ \\
\hline Elderly people don't like having fun & $\begin{array}{l}6 \% \\
(4)\end{array}$ & $\begin{array}{l}16 \% \\
(11)\end{array}$ & $\begin{array}{l}21 \% \\
(15)\end{array}$ & $\begin{array}{l}40 \% \\
(28)\end{array}$ & $\begin{array}{l}17 \% \\
(12)\end{array}$ \\
\hline $\begin{array}{l}\text { Elderly people can't take right decisions on } \\
\text { important issues }\end{array}$ & $\begin{array}{l}4 \% \\
(3)\end{array}$ & $\begin{array}{l}13 \% \\
(9)\end{array}$ & $\begin{array}{l}33 \% \\
(23)\end{array}$ & $\begin{array}{l}34 \% \\
(24)\end{array}$ & $\begin{array}{l}16 \% \\
(11)\end{array}$ \\
\hline Elderly people limit their social contacts & $\begin{array}{l}4 \% \\
(3)\end{array}$ & $\begin{array}{l}43 \% \\
(30)\end{array}$ & $\begin{array}{l}13 \% \\
(9)\end{array}$ & $\begin{array}{l}31 \% \\
(22)\end{array}$ & $\begin{array}{l}9 \% \\
(6)\end{array}$ \\
\hline $\begin{array}{l}\text { Elderly people suffer from increased } \\
\text { depression }\end{array}$ & $\begin{array}{l}14 \% \\
(10)\end{array}$ & $\begin{array}{l}37 \% \\
(26)\end{array}$ & $\begin{array}{l}19 \% \\
(13)\end{array}$ & $\begin{array}{l}24 \% \\
(17)\end{array}$ & $\begin{array}{l}6 \% \\
(4)\end{array}$ \\
\hline Elderly people are poorly work - efficient & $\begin{array}{l}17 \% \\
(12)\end{array}$ & $\begin{array}{l}30 \% \\
(21)\end{array}$ & $\begin{array}{l}14 \% \\
(10)\end{array}$ & $\begin{array}{l}24 \% \\
(17)\end{array}$ & $\begin{array}{l}14 \% \\
(10)\end{array}$ \\
\hline $\begin{array}{l}\text { Elderly people are not interested in the } \\
\text { surrounding world }\end{array}$ & $\begin{array}{l}4 \% \\
(3)\end{array}$ & $\begin{array}{l}17 \% \\
(12)\end{array}$ & $\begin{array}{l}17 \% \\
(12)\end{array}$ & $\begin{array}{l}43 \% \\
(30)\end{array}$ & $\begin{array}{l}19 \% \\
(13)\end{array}$ \\
\hline $\begin{array}{l}\text { Elderly people don't want or don't need } \\
\text { close relationships }\end{array}$ & $\begin{array}{l}4 \% \\
(3)\end{array}$ & $\begin{array}{l}9 \% \\
(6)\end{array}$ & $\begin{array}{l}23 \% \\
(16)\end{array}$ & $\begin{array}{l}27 \% \\
(19)\end{array}$ & $\begin{array}{l}37 \% \\
(26)\end{array}$ \\
\hline Elderly people don't like changes & $19 \%$ \\
$(13)$ & $\begin{array}{l}44 \% \\
(31)\end{array}$ & $\begin{array}{l}16 \% \\
(11)\end{array}$ & $\begin{array}{l}17 \% \\
(12)\end{array}$ & $\begin{array}{l}4 \% \\
(3)\end{array}$ \\
\hline
\end{tabular}

To the statement:"Elderly people do not like having fun" - $40 \% \quad(\mathrm{n}=28)$ have explicitly answered „no“.

Nowadays for most elderly people besides the traditional entertainments - watching $\mathrm{TV}$, participating in different clubs and ensembles, there are new opportunities that offer various forms of continuing education (language qualification courses and computer training), which gives them the opportunity to enter in new and useful activities. $44 \%(n=31)$ from the respondents have the opinion that elderly people do not like changes.
The research show that in many ways elderly people are positive towards changes because they realize ageing and so they prefer to stay open for the moments that create for them qualititative and satisfying life.

The biggest percent of the questioned $37 \%$ $(n=26)$ hold the opinion that elderly people are prone to increased depression. The manifestations of depression among the elderly individuals has no general tendency to increasing, its appearing in most cases corresponds to certain specific changes in the life of every person. 
„Elderly people are not very efficient in working"- $17 \%$ have explicitly answered „yes" and 30\% mostly „yes“. Participation in the working life is a significant positive factor in the active life of the elderly people, but with the age advancing there appear and increase individual differences in the work-efficiency. The realization that with age-advancing elderly people become non-productive and poorly efficient at work, are among the most widespread stereotypic beliefs. Practices, in conducted research, show that employers assess highly their elder employees and they value their personal skills, professional qualities and ethics.

\section{DEDUCTIONS}

The analyses of the conducted research allow us to make the following deductions:

- To a considerable degree the students share the existing in our society stereotypes concerning ageing and elderly people.

- The image of the elderly person is described mostly with negative rather than positive features.

- The stereotypic beliefs are prevailing and they represent elderly people with limited social contacts, increased depression, poor work - efficiency and conservatism in regards to the changes.

\section{RECOMMENDATIONS}

- In the training of the students to be applied various interactive techniques and approaches that present positive role models of ageing, i.e. teaching from the view-point of the positive ageing and formation of new types of attitudes and beliefs towards the elderly generation.

- Realization of a study process through giving the required relevant information connected to the problem ageism, explanatory models and influences.

- Encouraging interactions with the community and assessment of their needs and problems, which in turn will assist ignoring and distancing from the traditional, social ageist beliefs.

- Discussions on the problems of the age discrimination in the sphere of the healthcare.

\section{CONCLUSION}

The phenomenon „ageism“ places its challenges to the contemporary society and it require deep research and application of opportunities for its overcoming via adequate educational programs and models. Ageist beliefs are unhealthy and they do not correspond to the future practice of the nurses in accomplishing their geriatric care. It is very important that such correctional activities begin from change in the individual beliefs to realizing professional, competent support to the elderly people and encouraging active ageing. This is the right direction, whose only aim is counteraction against the prevailing segregation and discrimination of the elderly people.

\section{REFERENCES}

1. http://www.nsi.bg/

2. Ragan, A. M., Bowen, A. M. (2001). Improving Attitudes Regarding the Elderly Population: The Effects of Information and Reinforcement for Change. The Gerontologist.

3. Thompson, N. (2001). Anti-discriminatory practice (3rd ed). Basingstoke: Palgrave. Macmillan.

4. Eurobarometer: Age discrimination is mostly widespread in Bulgaria, 09.11.2009,

http://old.europe.bg/htmls/page.php?categor $\mathrm{y}=5 \& \mathrm{id}=25266$

5. Balkanska, P. Psychosocial and health perspectives of ageing, realities and opportunities for successful ageing, 2012

6. Petrova, D. Ageism, or stereotyping according to age: nature, effects and ways to study them, Sofia, 99: 397-412, 2010

7. Ivanov, P. Conflicts between generations, Stara Zagora, 2009 